\title{
Lithium and Zinc Sulfide Coated Plastic Neutron Detector Test
}

RT Kouzes

JH Ely

July 16, 2010

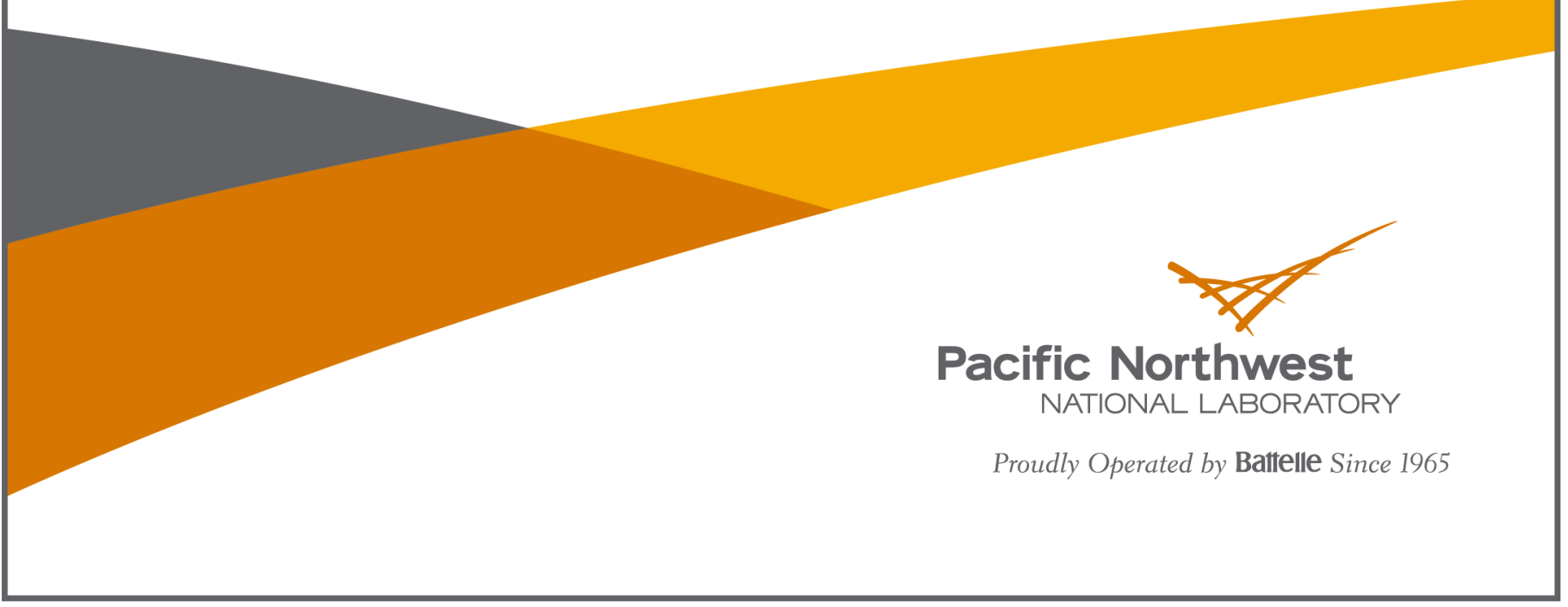




\title{
DISCLAIMER
}

This report was prepared as an account of work sponsored by an agency of the United States Government. Neither the United States Government nor any agency thereof, nor Battelle Memorial Institute, nor any of their employees, makes any warranty, express or implied, or assumes any legal liability or responsibility for the accuracy, completeness, or usefulness of any information, apparatus, product, or process disclosed, or represents that its use would not infringe privately owned rights. Reference herein to any specific commercial product, process, or service by trade name, trademark, manufacturer, or otherwise does not necessarily constitute or imply its endorsement, recommendation, or favoring by the United States Government or any agency thereof, or Battelle Memorial Institute. The views and opinions of authors expressed herein do not necessarily state or reflect those of the United States Government or any agency thereof.

\author{
PACIFIC NORTHWEST NATIONAL LABORATORY \\ operated by \\ BATTELLE \\ for the \\ UNITED STATES DEPARTMENT OF ENERGY \\ under Contract DE-AC05-76RL01830
}

Printed in the United States of America
Available to DOE and DOE contractors from the Office of Scientific and Technical Information,
P.O. Box 62, Oak Ridge, TN 37831-0062;
ph: (865) 576-8401
fax: $(865)$ 576-5728
email: reports@adonis.osti.gov

\begin{abstract}
Available to the public from the National Technical Information Service, U.S. Department of Commerce, 5285 Port Royal Rd., Springfield, VA 22161 ph: (800) 553-6847 fax: $(703) 605-6900$ email: orders@ntis.fedworld.gov online ordering: http://www.ntis.gov/ordering.htm
\end{abstract}

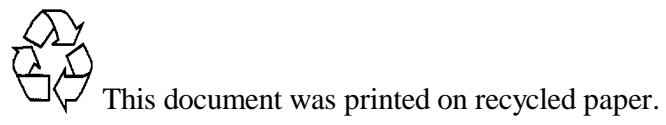


PNNL-19566

\section{Lithium and Zinc Sulfide Coated Plastic Neutron Detector Test}

RT Kouzes

JH Ely

July 16, 2010

Pacific Northwest National Laboratory

Richland, Washington 99352 


\section{Executive Summary}

Radiation portal monitors used for interdiction of illicit materials at borders include highly sensitive neutron detection systems. The main reason for having neutron detection capability is to detect fission neutrons from plutonium. The currently deployed radiation portal monitors (RPMs) from Ludlum and Science Applications International Corporation (SAIC) use neutron detectors based upon ${ }^{3} \mathrm{He}$-filled gas proportional counters, which are the most common large neutron detector. There is a declining supply of ${ }^{3} \mathrm{He}$ in the world, and thus, methods to reduce the use of this gas in RPMs with minimal changes to the current system designs and sensitivity to cargo-borne neutrons are being investigated.

Four technologies have been identified as being currently commercially available, potential alternative neutron detectors to replace the use of ${ }^{3} \mathrm{He}$ in RPMs. These technologies are:

1) Boron trifluoride $\left(\mathrm{BF}_{3}\right)$-filled proportional counters,

2) Boron-lined proportional counters,

3) Lithium-loaded glass fibers, and

4) Coated non-scintillating plastic fibers.

In addition, a few other companies have detector technologies that might be competitive in the near term as an alternative technology. Reported here are the results of tests of ${ }^{6} \mathrm{Li} / \mathrm{ZnS}(\mathrm{Ag})$-coated scintillator paddles. This testing measured the required performance for neutron detection efficiency and gamma ray rejection capabilities of a system manufactured by Symetrica.

The Symetrica neutron detection system has been tested and compared to ${ }^{3} \mathrm{He}$ as a possible alternative neutron detection technology. The Symetrica detector uses a wavelength shifting plastic paddle that is coated with ${ }^{6} \mathrm{Li}$ plus $\mathrm{ZnS}(\mathrm{Ag})$ to detect neutrons. Discrimination between neutrons and gamma rays is based on a proprietary analysis.

The tests were conducted on a Symetrica detector paddle with a surface area of $0.1 \mathrm{~m}$ x $1.0 \mathrm{~m}$. Results suggest that neutron detection efficiency comparable to existing ${ }^{3} \mathrm{He}$ detectors will be obtained if the detector's size is scaled up to occupy the available space of the present neutron detector system in the standard ${ }^{3}$ He-based RPM, assuming linear scaling. Such larger systems with multiple paddles will need to be tested to determine if there is a significant loss of efficiency in scaling up due to such effects as shadowing between detectors.

Test results indicate that adequate intrinsic gamma ray efficiency (gamma ray rejection) is obtained for gamma exposure rates up to $100 \mathrm{mR} / \mathrm{hr}$ for the one paddle tested. The gamma rejection factor is estimated to be on the order of $10^{-8}$ for a dose rates up to $40 \mathrm{mR} / \mathrm{hr}$, which is similar to that obtained for ${ }^{3} \mathrm{He}\left(\sim 10^{-8}\right)$. It seems likely that the intrinsic gamma ray efficiency of the full size neutron detector will meet the required value of $10^{-6}$ in a $10 \mathrm{mR} / \mathrm{hr}$ field.

The GARRn value at a ${ }^{60} \mathrm{Co}$ exposure rate of $10 \mathrm{mR} / \mathrm{hr}$ is within the desired range. Testing of a full size system designed for use as a replacement for the ${ }^{3} \mathrm{He}$ based system in deployed systems will need to be evaluated to see whether the GARRn value remains in the acceptable range.

The system tested demonstrates that this technology could meet the RPMP neutron detection requirements, but testing of a full scale detector is required. 


\section{Acronyms and Abbreviations}

ANSI

cps

GARRn

$\mathrm{mR} / \mathrm{h}$

PNNL

PolyBox

RPM

RSP

SAIC
American National Standards Institute

Counts per second

Gamma Absolute Rejection Ratio in the presence of neutrons

Milli-Roentgen per hour

Pacific Northwest National Laboratory

Polyethylene moderator/reflector box

Radiation Portal Monitor

Radiation Sensor Panel

Science Applications International Corporation 


\section{Contents}

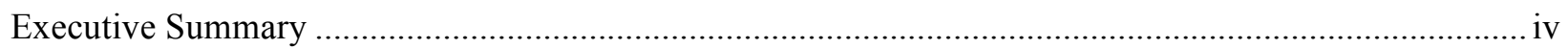

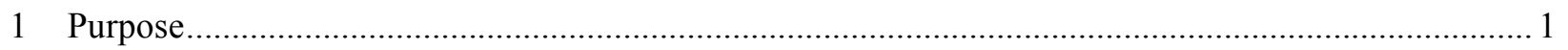

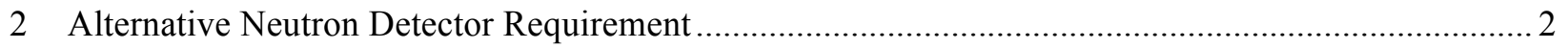

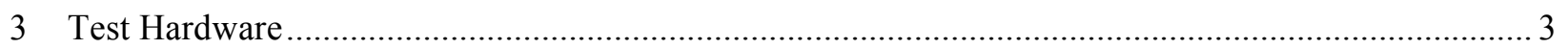

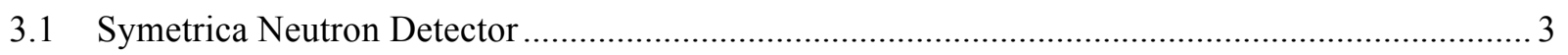

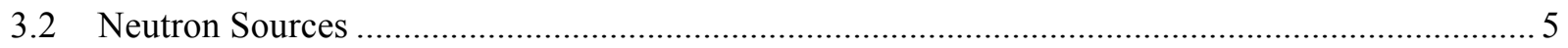

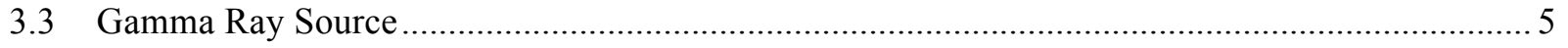

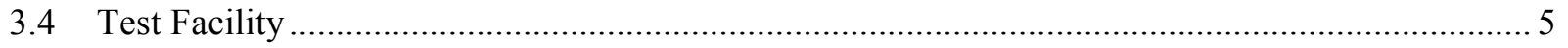

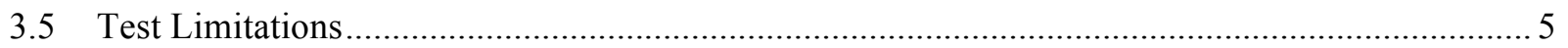

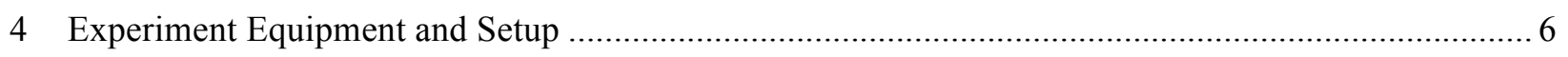

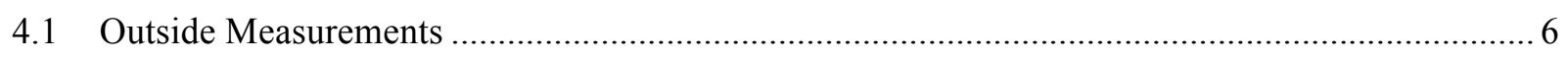

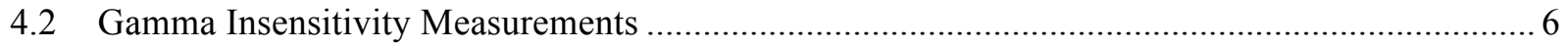

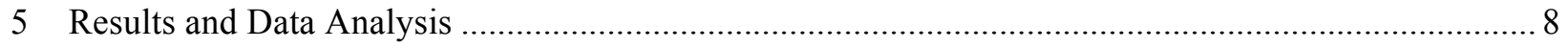

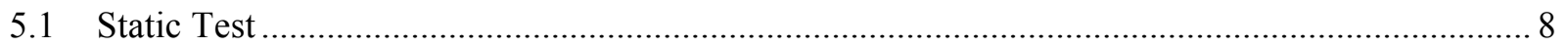

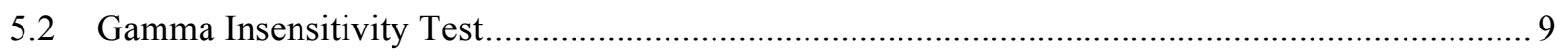

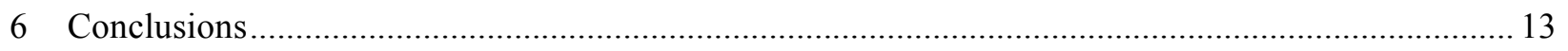

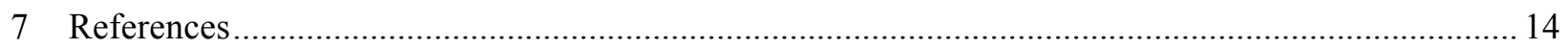




\section{Figures and Tables}

\section{Figures}

Figure 3.1: The Symetrica detector being tested outside at PNNL .................................................... 3

Figure 3.2: Symetrica detector mounted inside the SAIC RSP for testing. ............................................ 4

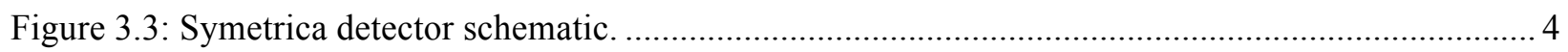

Figure 4.1. The Symetrica detector positioned for gamma insensitivity testing with the ${ }^{60}$ Co source in the background, the detector in the foreground and the neutron source in between. ............................. 7

Figure 4.2. The Symetrica detector positioned for gamma insensitivity testing with the ${ }^{60}$ Co source in the foreground, the detector in the background and the neutron source in between. ................................ 7

Figure 5.1. The Symetrica detector results for efficiency versus the "threshold parameter" for the system outside on a ladder.

Figure 5.2. The Symetrica detector results for efficiency versus the "threshold parameter" for the system

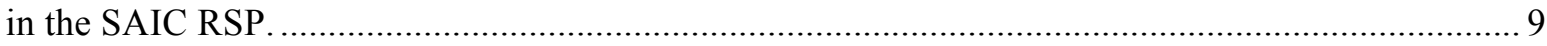

Figure 5.3. The Symetrica detector results for cps versus gamma ray exposure rate. ............................. 10

Figure 5.4: Best efficiency versus gamma ray exposure rate ............................................................... 11

Figure 5.5: GARRn versus gamma ray exposure rate...................................................................... 12

\section{Tables}

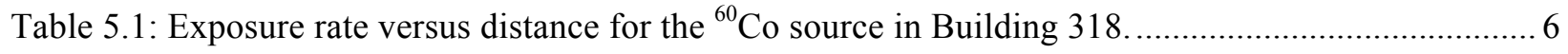

Table 5.1: Measurement results for a "threshold parameter" value of zero............................................... 10

Table 5.2: GARRn value versus "threshold parameter" for each gamma ray exposure rate, and the best $\mathrm{cps} / \mathrm{ng}$ found for a GARRn value within the acceptable range. ..................................................... 11 


\section{Purpose}

Radiation portal monitor (RPM) systems used for interdiction of illicit materials at borders include highly sensitive neutron detection systems. The main reason for having neutron detection capability is to detect fission neutrons from plutonium. The currently deployed radiation portal monitors from Ludlum and Science Applications International Corporation (SAIC) use neutron detectors based upon ${ }^{3} \mathrm{He}$-filled gas proportional counters, which are the most common large neutron detector.

Within the last few years, the amount of ${ }^{3} \mathrm{He}$ available for use in gas proportional counter neutron detectors has become more restricted, while the demand has significantly increased, especially for homeland security applications (Kouzes 2009). In the near future, limited supply is expected to curtail the use of ${ }^{3} \mathrm{He}$; therefore, alternative neutron detection technologies are being investigated for use in the radiation portal monitor systems being deployed for border security applications (Van Ginhoven 2009).

From a survey of technologies, only four technologies have been identified as currently commercially available, potential alternative neutron detectors to replace the use of ${ }^{3} \mathrm{He}$ in RPMs in the near-term. These technologies are:

1) Boron trifluoride $\left(\mathrm{BF}_{3}\right)$-filled proportional counters (from Reuter Stokes or LND),

2) Boron-lined proportional counters (from Reuter Stokes or LND),

3) Lithium-loaded glass fibers (from NucSafe), and

4) Coated non-scintillating plastic fibers (from Innovative American Technology [IAT]).

In addition, a few other companies have detector technologies that might be competitive in the near term as an alternative technology. Reported here are the results of tests by Pacific Northwest National Laboratory (PNNL) of ${ }^{6} \mathrm{Li}$ plus $\mathrm{ZnS}(\mathrm{Ag})$-coated scintillator paddles manufactured by Symetrica (Maynard, MA). This testing measured the required performance for neutron detection efficiency and gamma ray rejection capabilities. Responses of the system to moderated and un-moderated neutrons and to a high gamma-ray exposure rate to measure gamma sensitivity and GARRn (Kouzes et al., 2009) were measured. 


\section{Alternative Neutron Detector Requirement}

Scintillator coated paddles are a variation on the geometry of coated fiber detectors and are a possible neutron detector replacement technology for ${ }^{3} \mathrm{He}$-filled tubes. The Symetrica detector can be made with dimensions that will fit in the space available for the currently deployed standard ${ }^{3} \mathrm{He}$-based RPM polyethylene box that contains the ${ }^{3} \mathrm{He}$ tubes in the SAIC RPM system. A system for replacement of the current neutron detectors in a standard ${ }^{3} \mathrm{He}$-based RPM must fit within the space occupied by the present ${ }^{3}$ He-based neutron detection system $[0.114 \mathrm{~m}$ deep x $0.304 \mathrm{~m}$ wide $\times 2.18 \mathrm{~m}$ tall $(4.5 \mathrm{in} . \times 12 \mathrm{in} . \times$ 85.7in.)] in the SAIC RPM system.

The standard ${ }^{3}$ He-based systems were purchased under a specification (Stromswold et al., 2003) that requires a single radiation sensor panel (RSP) to meet the following requirements:

“A ${ }^{252} \mathrm{Cf}$ neutron source will be used for testing neutron sensor sensitivity:

- To reduce the gamma-ray flux, the source shall be surrounded by at least $0.5 \mathrm{~cm}$ of lead. To moderate the neutron spectrum, $2.5 \mathrm{~cm}$ of polyethylene shall be placed around the source.

- The absolute detection efficiency for such $\mathrm{a}^{252} \mathrm{Cf}$ source, located $2 \mathrm{~m}$ perpendicular to the geometric midpoint of the neutron sensor, shall be greater than $2.5 \mathrm{cps} / \mathrm{ng}$ of ${ }^{252} \mathrm{Cf}$. The neutron detector center shall be $1.5 \mathrm{~m}$ above grade for this test. (Note: 10 nanograms of ${ }^{252} \mathrm{Cf}$ is equivalent to 5.4 micro-Ci or $2.1 \times 10^{4} \mathrm{n} / \mathrm{s},{ }^{1}$ since ${ }^{252} \mathrm{Cf}$ has a $3.092 \%$ spontaneous fission (SF) branch and 3.757 neutrons/SF.)

- The neutron detector shall not generate alarms due to the presence of strong gamma-ray sources. The ratio of neutron sensor gamma-ray detection efficiency to neutron detection shall be less than 0.001."

To evaluate the performance of alternate neutron detectors compared to what is currently deployed three criteria are considered: 1) absolute neutron detection efficiency, 2) intrinsic efficiency of gamma rays detected as neutrons, and 3) Gamma Absolute Rejection Ratio in the presence of neutrons (GARRn) (Kouzes et al., 2009).

The absolute neutron detection efficiency $\left(\epsilon_{\text {abs n }}\right)$ required is that previously specified $(2.5 \mathrm{cps} / \mathrm{ng}$ from a ${ }^{252} \mathrm{Cf}$ source at $2 \mathrm{~m}$ in a specified pig). The intrinsic efficiency of gammas detected as neutrons $\left(\epsilon_{\text {int }} \mathrm{\gamma n}\right)$ is the number of events that are counted as neutrons in the presence of a gamma source divided by the number of photons hitting the detector area, and shall be less than $10^{-6}$ at an exposure rate of $10 \mathrm{mR} / \mathrm{h}$. The GARRn is the number of events that are counted as neutrons $\left(\epsilon_{\mathrm{abs} \gamma \mathrm{n}}\right)$ in the presence of both a gamma ray and neutron source divided by the number of neutrons recorded without the gamma ray source $\left(\epsilon_{\text {abs }}\right)$, the requirement for this parameter is that $0.9 \leq \mathrm{GARRn} \leq 1.1$ at a $10 \mathrm{mR} / \mathrm{h}$ gamma exposure rate.

In addition, these systems are required to meet all aspects of the ANSI N42.35 standard (ANSI 2006). A summary of neutron detection systems in RPMs can be found in a PNNL report (Kouzes et al., 2007).

\footnotetext{
${ }^{1} 2.3 \times 10^{4} \mathrm{n} / \mathrm{s}$ is the currently used best known value
} 


\section{Test Hardware}

\subsection{Symetrica Neutron Detector}

The Symetrica neutron detector uses a wavelength-shifting plastic paddle that is coated with a mixture of ${ }^{6} \mathrm{Li}$ and $\mathrm{ZnS}(\mathrm{Ag})$. The Symetrica detector size currently available has a detection area of $0.1 \mathrm{~m}$ wide by $1.0 \mathrm{~m}$ long, a thickness of $20 \mathrm{~mm}$, and is encased in a polyethylene moderator of outside dimension $0.2 \mathrm{~m}$ $\mathrm{x} 1.1 \mathrm{~m} \mathrm{x} 0.1 \mathrm{~m}$. On the front side of the paddle the polyethylene is $25 \mathrm{~mm}$ thick and on the backside it is $50 \mathrm{~mm}$ thick. The paddle is viewed at one end by a $51 \mathrm{~mm}$ diameter photomultiplier tube. Figure 3.1 shows the detector in the polyethylene moderator sitting on a ladder for measurements outside at PNNL. The detector is covered with a thin sheet of $\mathrm{Cu}$ (painted white) to block low energy gamma rays. The control box and the photomultiplier tube and base can be seen on the left of the detector. Figure 3.2 shows the detector inserted into the SAIC radiation sensor panel (RSP) for testing in situ.

The ${ }^{6} \mathrm{Li}$ plus $\mathrm{ZnS}(\mathrm{Ag})$ coating serves as neutron absorber and phosphor. Thermal neutrons interact via the ${ }^{6} \mathrm{Li}(\mathrm{n}, \alpha)^{3} \mathrm{H}$ reaction, and the resultant charged particles produce light in the zinc sulfide. This light stimulates emission in the wavelength shifting plastic paddle that then conducts the light to the photomultiplier tube.

The electronics for the detector process the signals to provide the neutron (and gamma ray) count rate. A USB port on the control box connects to a computer that runs a user interface for data taking.

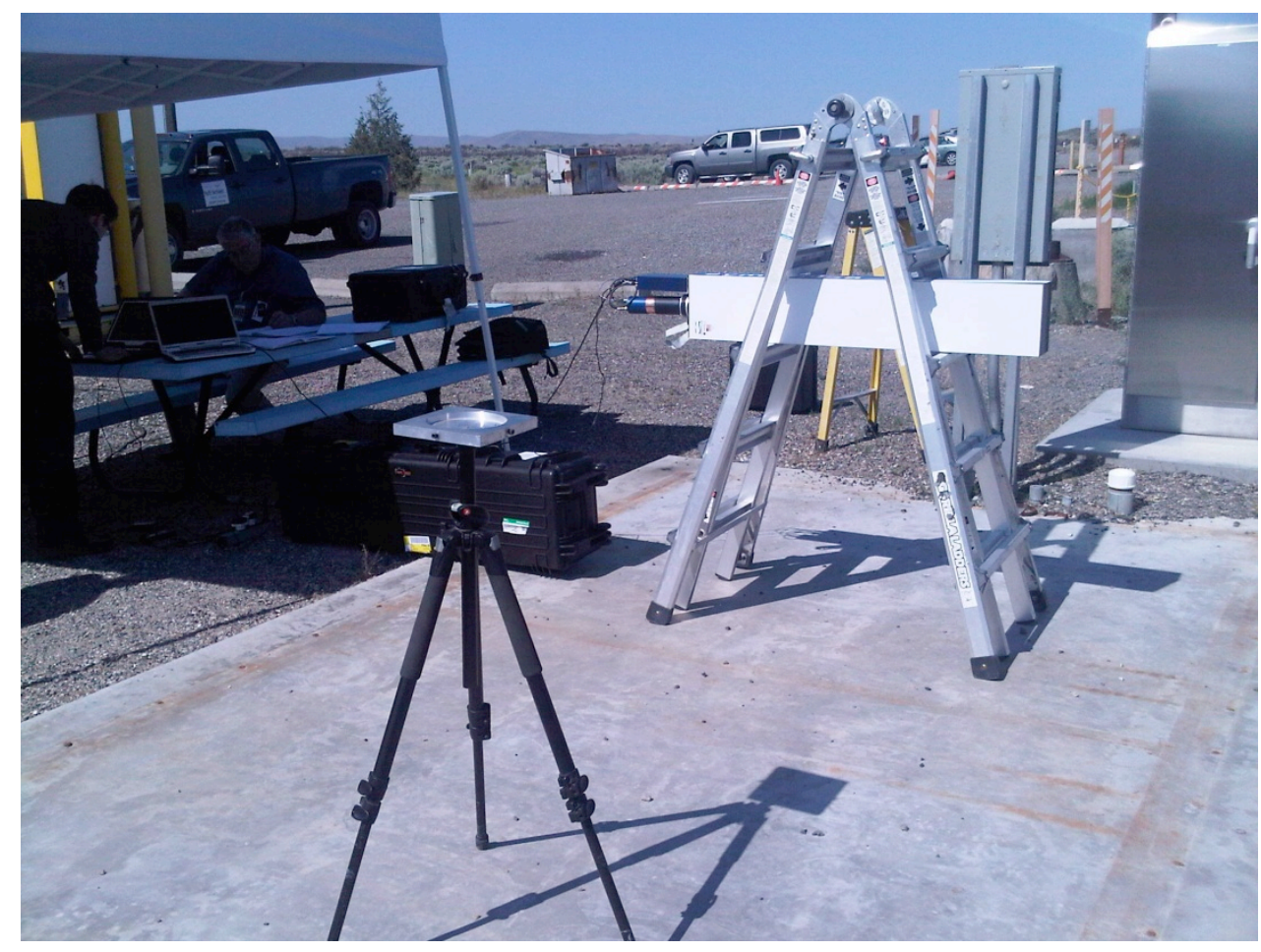

Figure 3.1: The Symetrica detector being tested outside at PNNL. 


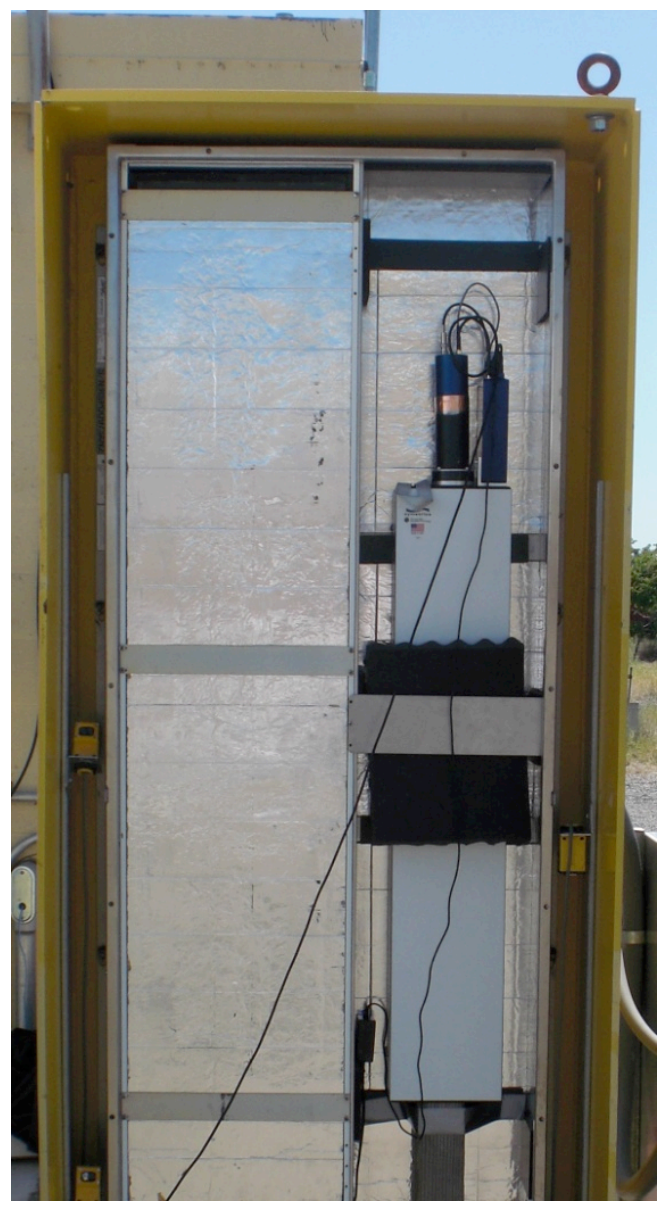

Figure 3.2: Symetrica detector mounted inside the SAIC RSP for testing.

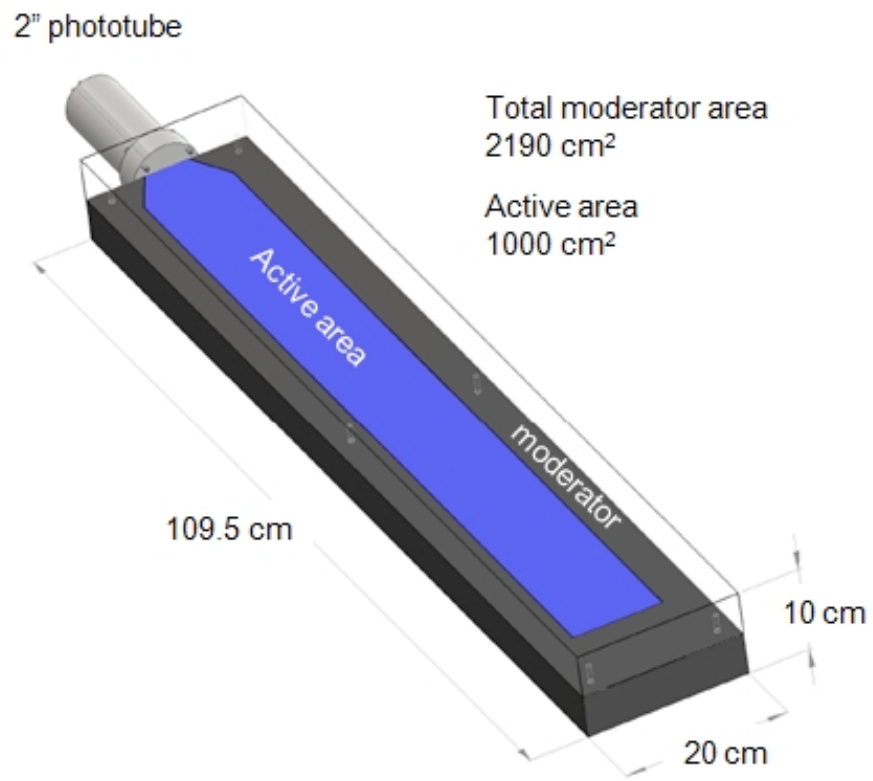

Figure 3.3: Symetrica detector schematic. 


\subsection{Neutron Sources}

The neutron source used for this test was ${ }^{252} \mathrm{Cf}$, with a halflife of 2.645 years. The source was purchased from Isotope Products Laboratory (IPL) and given a PNNL ID of 60208-44. The source was measured by IPL to be $21.91 \pm 1.25 \mu \mathrm{Ci}$ on October 1,2009 . The source used was estimated to be $18.16 \mu \mathrm{Ci}$ on the date of the tests (June 22, 2010). This activity corresponds to $33.6 \mathrm{ng}$ and an emanation rate of $7.7 \times 10^{4}$ $\mathrm{n} / \mathrm{s}$ with the conversion factor stated in Section 2 . This same neutron source was used the next day when the gamma sensitivity of the detector was being tested.

The source was used in two configurations; 1) moderated ( $25 \mathrm{~mm}$ of polyethylene moderator outside of 5 $\mathrm{mm}$ of lead) and 2) bare (encased only in a stainless steel enclosure).

\subsection{Gamma Ray Source}

A ${ }^{60}$ Co gamma ray source located in the Radiological Calibrations Laboratory in Building 318 at PNNL was used for the gamma ray sensitivity test. The exposure rate as a function of distance from the ${ }^{60} \mathrm{Co}$ source was determined by staff at the facility. The source strength was $106.7 \mathrm{mCi}$ on June 23, 2010 .

\subsection{Test Facility}

The tests were performed at PNNL at the $331 \mathrm{G}$ Integration Test Facility and the 318 Radiological Calibrations Laboratory located in Richland, WA. The outside tests were performed at the $331 \mathrm{G}$ building at PNNL. The gamma ray insensitivity measurements with the ${ }^{60} \mathrm{Co}$ source were performed at building 318.

\subsection{Test Limitations}

There were several limitations for this test and results may change with different conditions.

- Only one test location for each of the measurements was used, with the corresponding background. Since the testing was focused on net results (background subtracted) this should have little effect on the overall results.

- Only one detector system was tested. Results may change with different detector geometries.

- Uncertainty in the source strength was the main limitation to the test results. 


\section{Experiment Equipment and Setup}

\subsection{Outside Measurements}

Static measurements were made first with the detector on a ladder (Figure 3.1) and then with the detector inside the SAIC RSP (Figure 3.2). For the first measurements, the detector system was situated on the ladder so that the center of the detector was $0.98 \mathrm{~m}$ from the ground. The neutron source was located on a tripod $2 \mathrm{~m}$ from the front panel of the detector housing and at a height that positioned the source in the center of the detector. For the second measurement, the detector was placed vertically in the SAIC RSP in place of the standard ${ }^{3} \mathrm{He}$ moderator assembly (PolyBox) and the door of the RSP was closed.

Data were acquired over five minute time intervals for background and with the source for several different parameter settings. A "threshold parameter" in the Symetrica detector was adjusted (between values of -2 to +2 ) to observe the change in efficiency of the detector. The static measurements were used to obtain data that allowed the Symetrica detector efficiency to be compared to the efficiency of the ${ }^{3} \mathrm{He}$ tubes used in the current systems.

\subsection{Gamma Insensitivity Measurements}

The detector sensitivity to gamma rays was tested with a high-activity ${ }^{60} \mathrm{Co}$ sources in Building 318 to flood the entire detector system with a high gamma ray exposure rate. Table 4.1 shows the source-todetector face distance used for each of the indicated exposure rates.

Measurements were also made with the neutron source and the ${ }^{60} \mathrm{Co}$ source present simultaneously to determine the GARRn value and the gamma-ray rejection factor. For these indoor measurements, the neutron source was placed at the back of the detector so as not to block the gamma ray flux from the detector. Although the neutron sensitivity is different than when the neutron source is placed in front of the detector system, this location was only used to measure the relative change in efficiency with and without the gamma source (GARRn), and did not contribute to the absolute measurement.

Table 4.1: Exposure rate versus distance for the ${ }^{60} \mathrm{Co}$ source in Building 318.

$\begin{array}{cc}\mathbf{m R} / \mathbf{h} & \begin{array}{c}\text { Distance } \\ \text { (cm) }\end{array} \\ 5 & 521 \\ 10 & 369 \\ 20 & 261 \\ 40 & 184 \\ 50 & 165 \\ 60 & 150 \\ 100 & 117\end{array}$

The ${ }^{60} \mathrm{Co}$ gamma-sensitivity measurements were made with the detector placed on top of two stands at the height of the gamma ray source, as seen in figure 4.1. The detector was moved to different distances from the source to obtain the desired exposure rates on the detector's front face when the source was in position. Three-minute measurements were made for different scenarios at each position:

1. Background 
2. ${ }^{60}$ Co source in place

3. ${ }^{60} \mathrm{Co}$ source in place and the neutron source located on a tripod $2 \mathrm{~m}$ from the back of the detector. Measurements were made with a range of "threshold parameter" settings ranging from -2 to +6 .

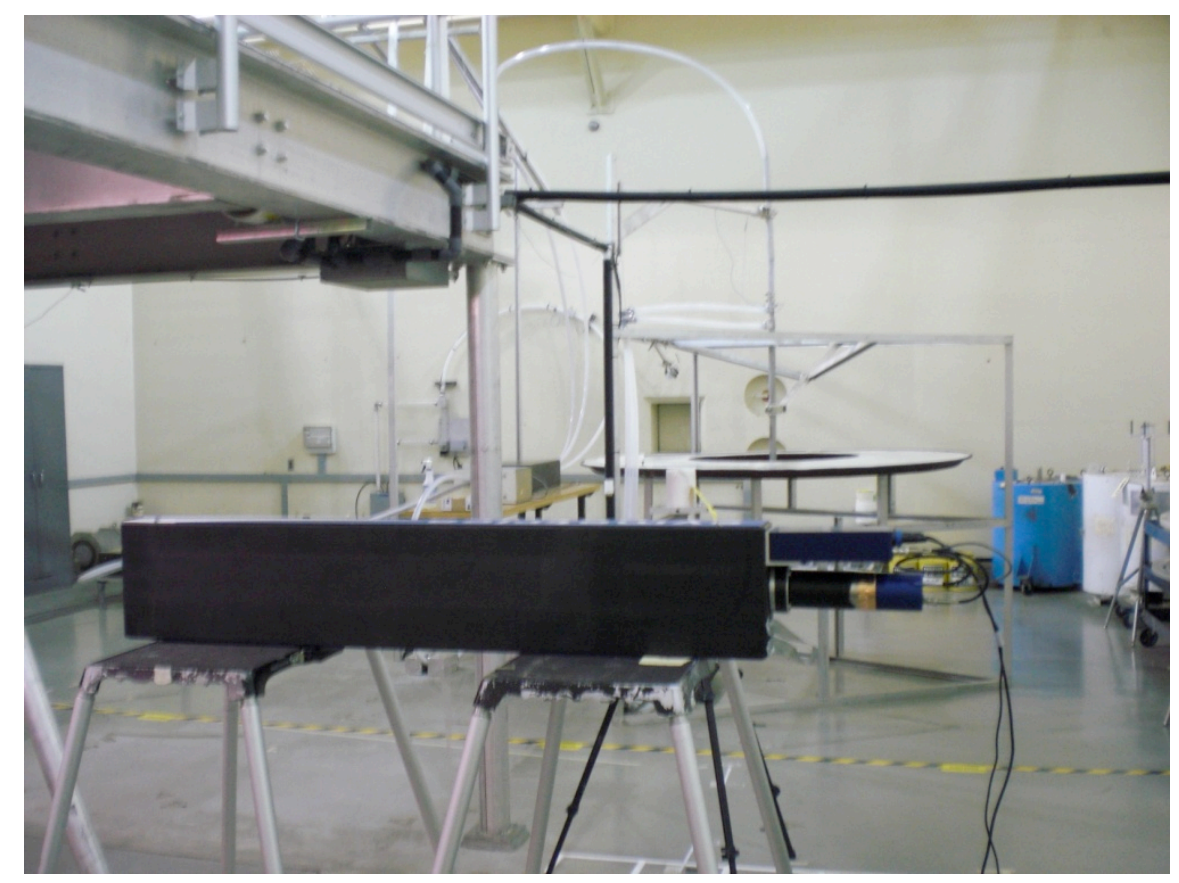

Figure 4.1. The Symetrica detector positioned for gamma insensitivity testing with the ${ }^{60} \mathrm{Co}$ source in the background, the detector in the foreground and the neutron source in between.

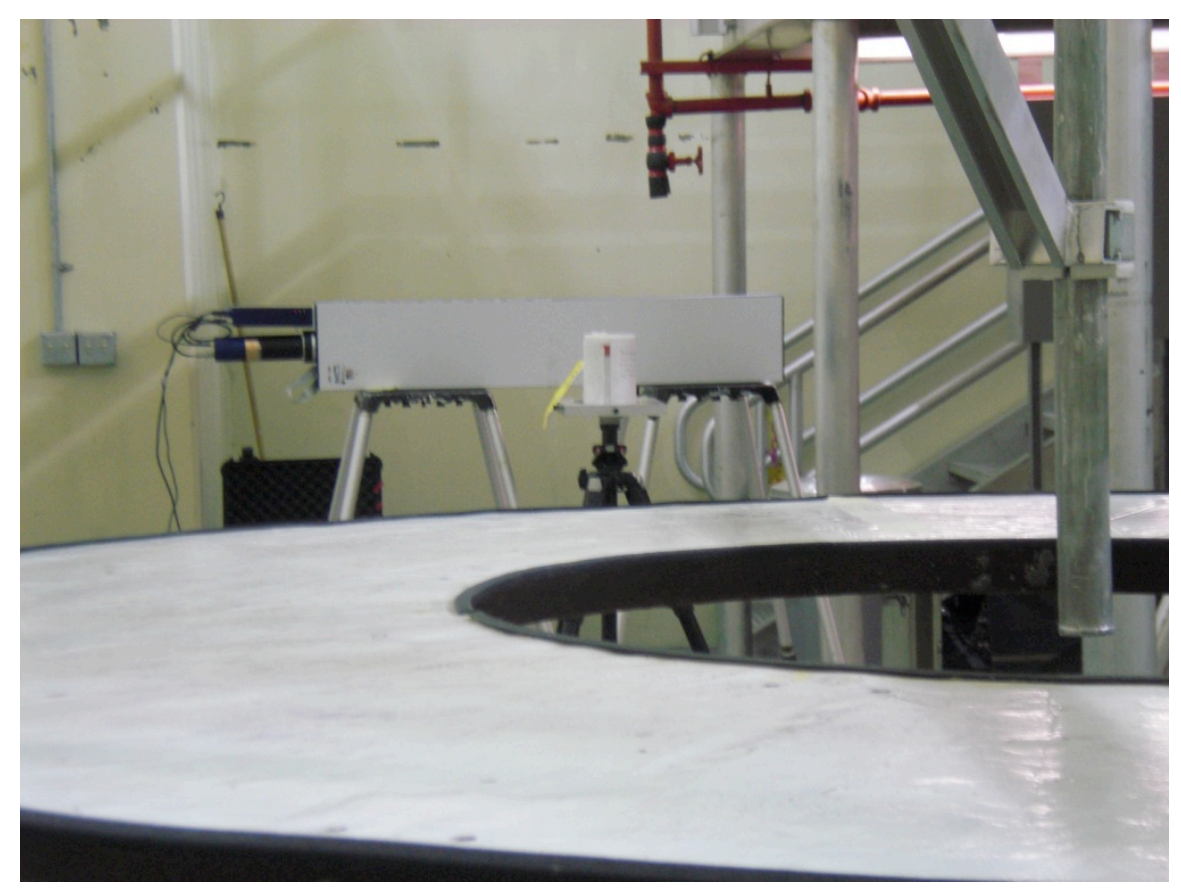

Figure 4.2. The Symetrica detector positioned for gamma insensitivity testing with the ${ }^{60} \mathrm{Co}$ source in the foreground, the detector in the background and the neutron source in between. 


\section{Results and Data Analysis}

\subsection{Static Test}

The data were collected with the Symetrica system software provided by the vendor. The data derived from the static tests were an average number of cps. Backgrounds were acquired and subsequently subtracted from each test configuration to provide the net count rate. The uncertainty in the absolute values obtained was dominated by the uncertainty in the neutron source strengths.

The net counts per second per ng of ${ }^{252} \mathrm{Cf}$ versus the "threshold parameter" are plotted in Figure 5.1 for the detector mounted on a ladder and out of doors. The default parameter value is zero. Assuming that the system tested were scaled up by a factor of four, which would fit in the standard volume available in the SAIC system, for a parameter value of zero the expected efficiency would be about $3.5 \mathrm{cps} / \mathrm{ng}$, which exceeds the required $2.5 \mathrm{cps} / \mathrm{ng}$.

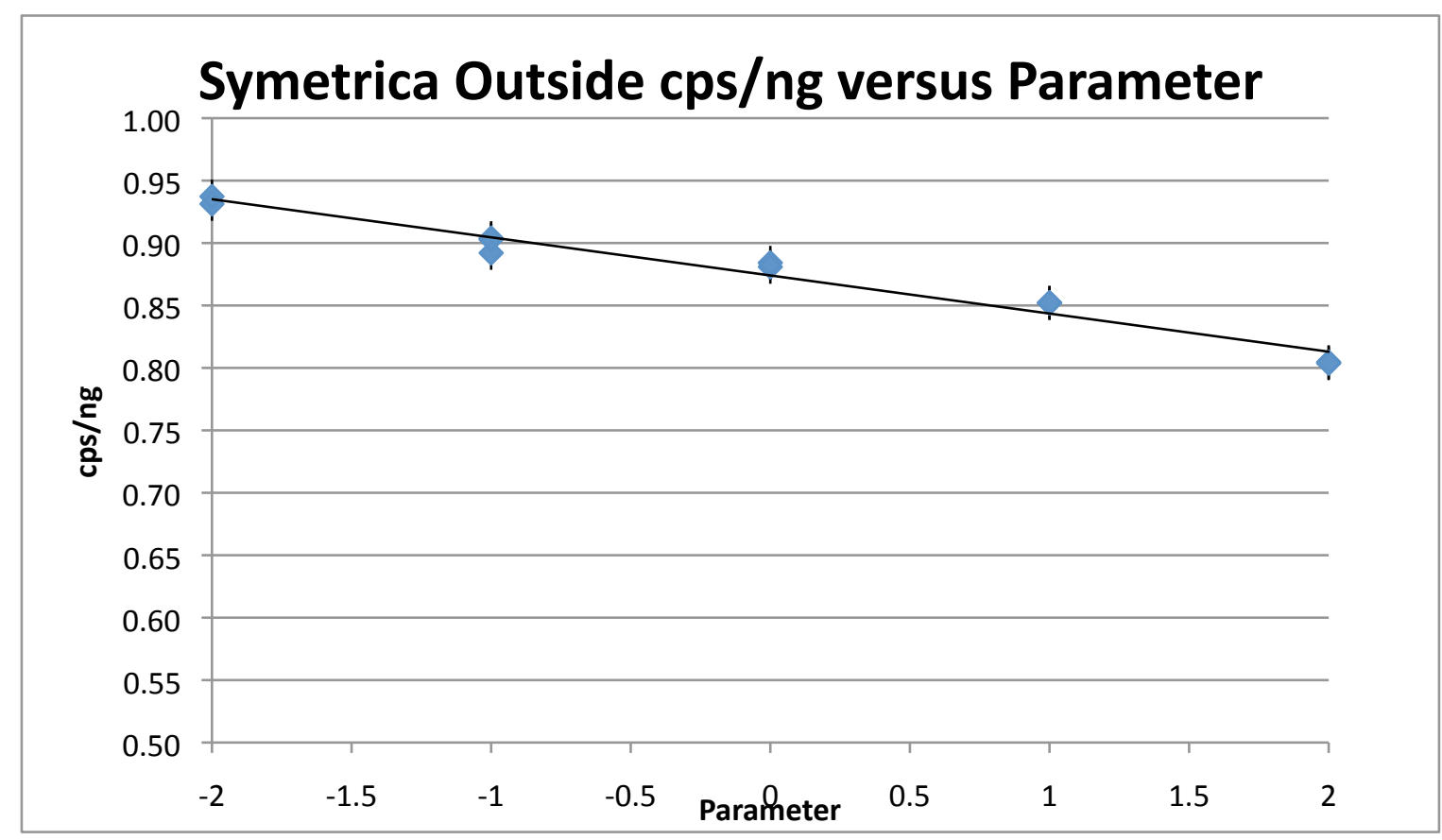

Figure 5.1. The Symetrica detector results for efficiency versus the "threshold parameter" for the system outside on a ladder.

The net counts per second per ng of ${ }^{252} \mathrm{Cf}$ versus the "threshold parameter" are plotted in Figure 5.2 for the detector mounted inside the SAIC RSP. The values with the door to the RSP off are slightly higher than with the door on. The efficiency values in the RSP are about $13 \%$ larger with the detector vertical than for the system outside the SAIC RSP and horizontal. The efficiency for a bare ${ }^{252} \mathrm{Cf}$ source is less than that of a moderated source by about $18 \%$. Assuming that the system tested in the RSP were scaled up by a factor of four, which would fit in the standard volume available in the SAIC system, for a parameter value of zero (which meets the GARRn requirement as discussed in the following section) the expected efficiency would be about $4 \mathrm{cps} / \mathrm{ng}$, which would exceed the required $2.5 \mathrm{cps} / \mathrm{ng}$. A larger Symetrica system (such as one using four paddles) will have to be tested to ensure that the system efficiency increases linearly with surface area. 


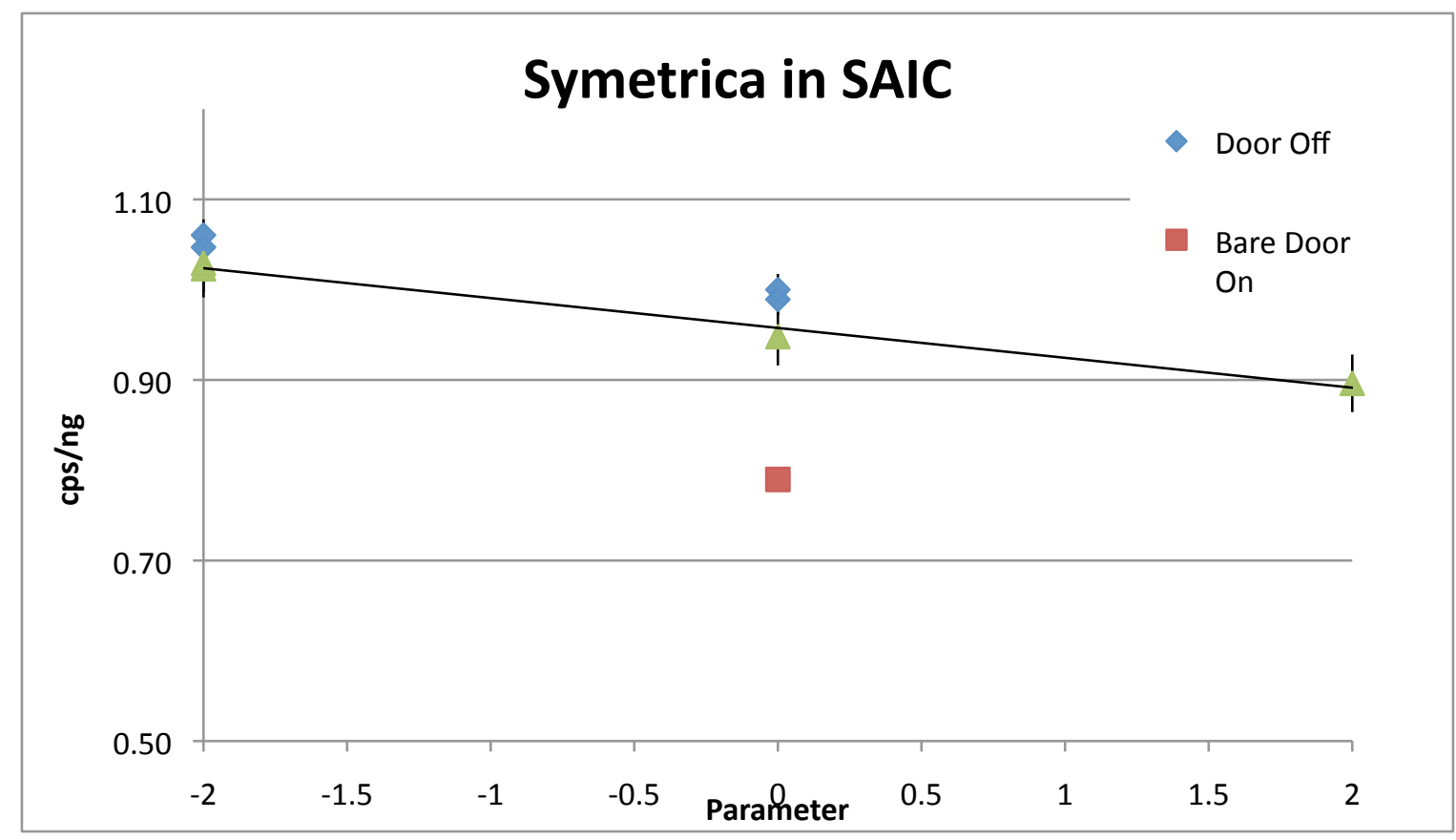

Figure 5.2. The Symetrica detector results for efficiency versus the "threshold parameter" for the system in the SAIC RSP.

\subsection{Gamma Insensitivity Test}

The detector sensitivity to gamma rays was tested with a ${ }^{60} \mathrm{Co}$ sources flooding the entire detector area with a high exposure rate gamma ray field.

The detector was able to discriminate between neutrons and gamma rays with a ${ }^{60} \mathrm{Co}$ source up to exposure rates of $100 \mathrm{mR} / \mathrm{hr}$ with reduced efficiency. For the GARRn measurements, the neutron source was placed $2 \mathrm{~m}$ from the back of the detector rather than the front in order not to shadow the detector from the gamma ray source. This results in a lower efficiency value but this cancels out in the GARRn calculation.

The gamma ray flux at the detector was estimated with the effective activity, which was calculated from the measured exposure rate at the detector, two gamma rays per decay, and the gamma factor for ${ }^{60} \mathrm{Co}$ $\left(13.2 \mathrm{R} \cdot \mathrm{cm}^{2} / \mathrm{hr} \cdot \mathrm{mCi}\right)$. The effective activity is defined as the source activity that would be required to produce the measured exposure rate at the distance from the source the detector was located. The effective activity was used to calculate the flux of gamma rays on the detector's active surface area.

Values for the intrinsic gamma ray efficiency and GARRn can be estimated from the calculated photon flux and the un-scaled neutron efficiency. The neutron efficiency used to calculate GARRn for each gamma exposure was the efficiency associated with each particular measurement. Thus, any geometric effects are divided out of the results. The results of the measurements for a "threshold parameter" value of zero are given in Table 5.1. For each exposure rate from 5 to $100 \mathrm{mR} / \mathrm{h}$, the table shows the background cps, the cps with only the gamma ray source, the cps and cps/ng for only the neutron source, and the cps for the combined neutron and gamma ray sources. For a threshold parameter setting of zero, the GARRn value is seen to be within the acceptable range $(0.9 \leq \mathrm{GARRn} \leq 1.1)$ for exposure rates up to $40 \mathrm{mR} / \mathrm{h}$, but outside that range for higher exposure rates. Figure 5.3 shows this information graphically. The intrinsic 
gamma ray efficiency shown in the table (Gamma Rejection) is below the required value of $10^{-6}$ for exposure rates up to $100 \mathrm{mR} / \mathrm{hr}$.

Table 5.1: Measurement results for a "threshold parameter" value of zero.

\begin{tabular}{|c|c|c|c|c|c|c|c|}
\hline $\begin{array}{c}\mathrm{mR} / \mathrm{h} \\
\text { Position }\end{array}$ & $\begin{array}{c}\text { Background } \\
\text { cps }\end{array}$ & $\begin{array}{c}\text { Gamma } \\
\text { cps }\end{array}$ & $\begin{array}{c}{ }^{252} \mathrm{Cf} \\
\mathrm{cps}\end{array}$ & $\begin{array}{l}{ }^{252} \mathrm{Cf} \\
\mathrm{cps} / \mathrm{ng}\end{array}$ & $\begin{array}{c}\text { Gamma } \\
+\mathrm{Cf} \\
\text { cps }\end{array}$ & GARRn & $\begin{array}{c}\text { Gamma } \\
\text { Rejection }\end{array}$ \\
\hline 5 & 0.21 & 0.22 & 27.73 & 0.82 & 27.57 & 0.99 & $2.5 \times 10^{-8}$ \\
\hline 10 & & 0.29 & 24.98 & 0.74 & 26.13 & 1.05 & $1.6 \times 10^{-8}$ \\
\hline 20 & 0.22 & 0.22 & 24.98 & 0.74 & 25.84 & 1.03 & $0.6 \times 10^{-8}$ \\
\hline 40 & 0.23 & 1.22 & 25.97 & 0.77 & 27.16 & 1.05 & $1.7 \times 10^{-8}$ \\
\hline 50 & 0.17 & 5.92 & 24.76 & 0.74 & 30.78 & 1.24 & $6.6 \times 10^{-8}$ \\
\hline 60 & 0.23 & 9.71 & 25.22 & 0.75 & 35.14 & 1.39 & $8.9 \times 10^{-8}$ \\
\hline 100 & & 100.39 & 23.86 & 0.71 & 116.52 & 4.88 & $56 \times 10^{-8}$ \\
\hline
\end{tabular}

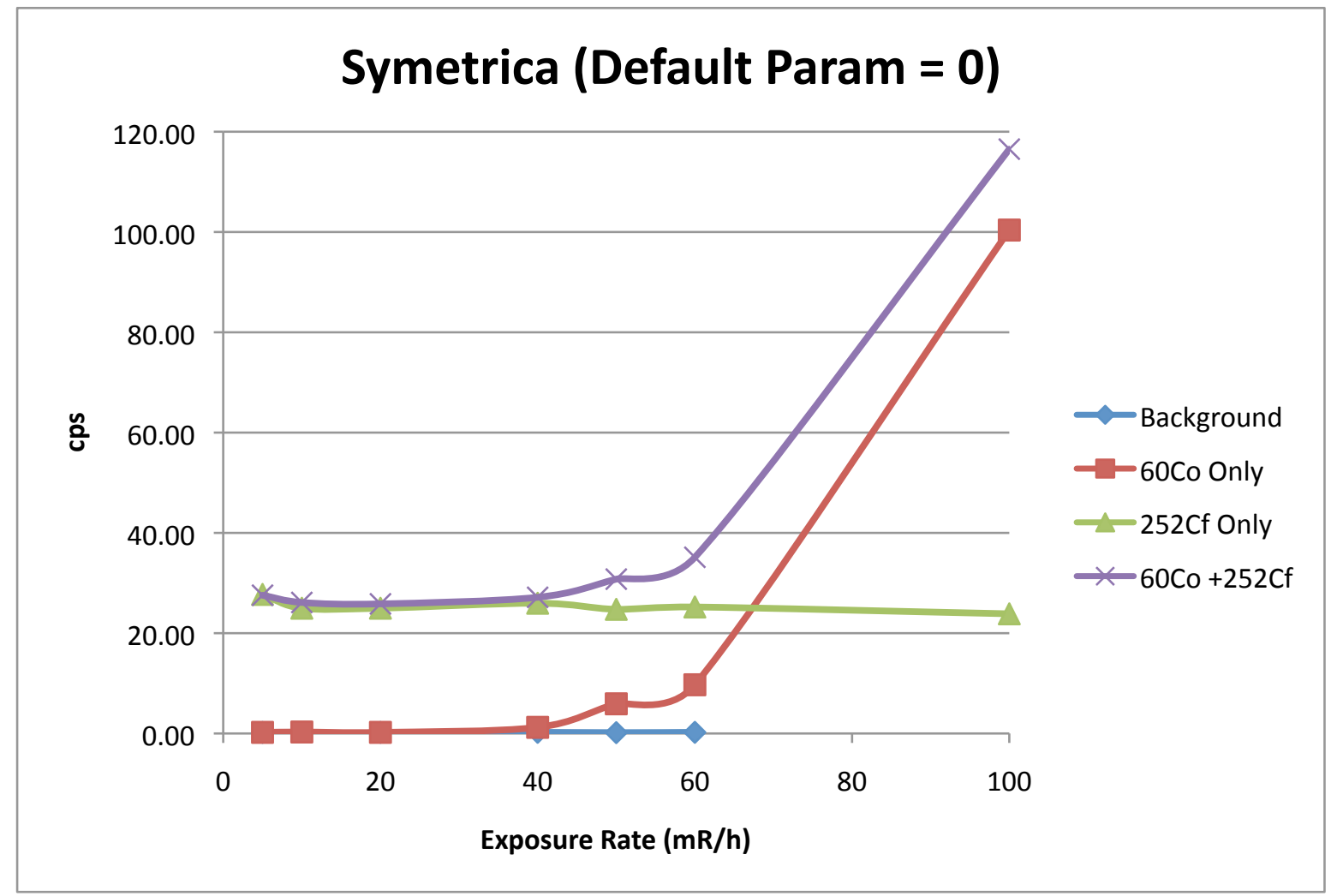

Figure 5.3. The Symetrica detector results for cps versus gamma ray exposure rate.

Table 5.2 gives the GARRn values for each gamma-ray exposure rate versus "threshold parameter," and the best cps/ng found for a GARRn value within the acceptable range (shown in bold). By increasing the parameter, which resulted in the reduced efficiency shown (under heading "Best"), the detector was able 
to continue to operate with an acceptable GARRn up to $100 \mathrm{mR} / \mathrm{h}$. This efficiency (measured $2 \mathrm{~m}$ from the back of the detector) is shown graphically in Figure 5.4.

Table 5.2: GARRn value versus "threshold parameter" for each gamma ray exposure rate, and the best cps/ng found for a GARRn value within the acceptable range.

\begin{tabular}{|crrrrrr|}
\hline $\begin{array}{c}\text { Position } \\
\text { mR/h }\end{array}$ & $\begin{array}{r}\text { Param = 0 } \\
\text { GARRn }\end{array}$ & $\begin{array}{c}\text { Param = -2 } \\
\text { GARRn }\end{array}$ & $\begin{array}{c}\text { Param = 2 } \\
\text { GARRn }\end{array}$ & $\begin{array}{c}\text { Param }=4 \\
\text { GARRn }\end{array}$ & $\begin{array}{c}\text { Param = 6 } \\
\text { GARRn }\end{array}$ & $\begin{array}{r}\text { Best } \\
\text { cps/ng }\end{array}$ \\
5 & $\mathbf{0 . 9 9}$ & 0.97 & 1.02 & & & 0.82 \\
10 & $\mathbf{1 . 0 5}$ & 1.01 & 0.99 & & & 0.74 \\
20 & $\mathbf{1 . 0 3}$ & & & & & 0.74 \\
40 & $\mathbf{1 . 0 5}$ & 1.24 & 1.02 & & & 0.77 \\
50 & 1.24 & & & & & \\
60 & 1.39 & 2.54 & 1.11 & $\mathbf{1 . 0 1}$ & & 0.64 \\
100 & 4.88 & & & 1.36 & $\mathbf{1 . 0 6}$ & 0.58 \\
\hline
\end{tabular}

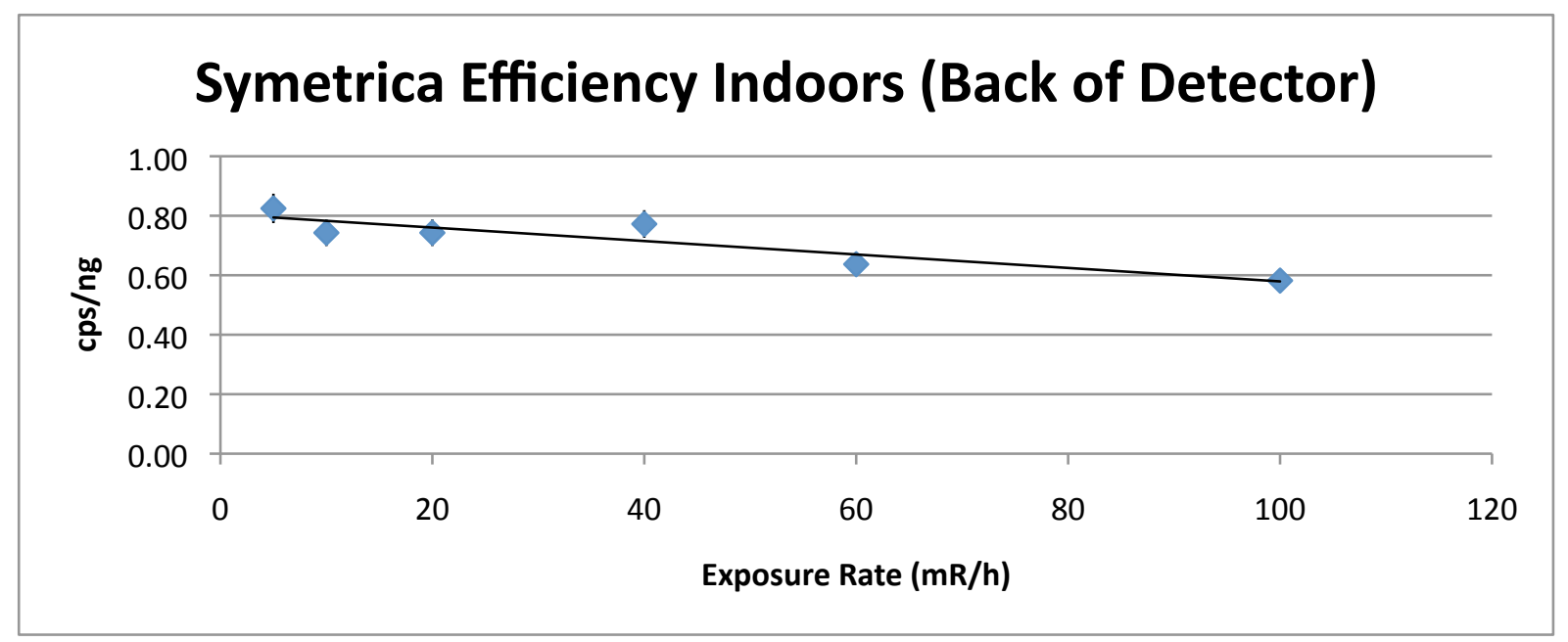

Figure 5.4: Best efficiency versus gamma ray exposure rate.

Figure 5.5 shows the GARRn versus exposure rate for various values of the "threshold parameter," where the band shown around one is the desired window $(0.9 \leq \mathrm{GARRn} \leq 1.1)$. As indicated in the table, the GARRn requirement can be met for some value of the "threshold parameter" at all exposure rates tested.

These results indicate that the Symetrica detector may have adequate gamma ray insensitivity to allow use in fielded systems but there is some loss of neutron efficiency in the presence of high gamma exposure rates. However, testing of a full size unit will be required before this capability will be fully known. 


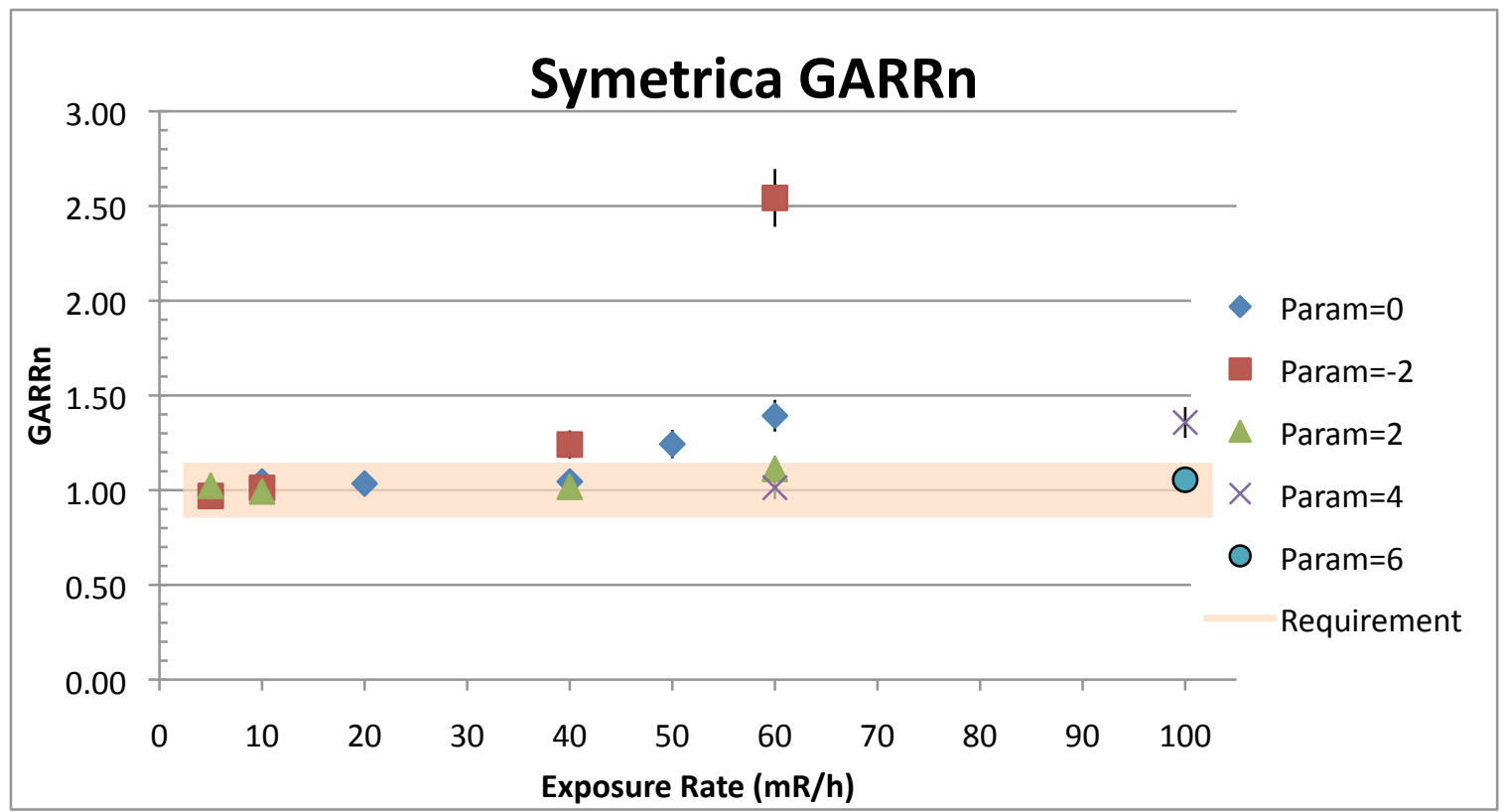

Figure 5.5: GARRn versus gamma ray exposure rate. 


\section{Conclusions}

The Symetrica neutron detection system has been tested and compared to ${ }^{3} \mathrm{He}$ as a possible alternative neutron detection technology. The Symetrica detector uses a wavelength shifting plastic paddle that is coated with ${ }^{6} \mathrm{Li}$ plus $\mathrm{ZnS}(\mathrm{Ag})$ to detect neutrons. Discrimination between neutrons and gamma rays is based on a proprietary analysis.

The tests were conducted on a Symetrica detector with a surface area of $0.1 \mathrm{~m} \times 1.0 \mathrm{~m}$. Results suggest that neutron detection efficiency comparable to existing ${ }^{3} \mathrm{He}$ detectors will be obtained if the size of the detector is scaled to occupy the available space of the present neutron detector system in the standard ${ }^{3} \mathrm{He}$-based RPM. Assuming linear scaling of the results reported here to the size to fit in the SAIC RSP, a unit with four paddles would have an efficiency of about $4 \mathrm{cps} / \mathrm{ng}$. Such larger systems will need to be tested to determine if there is a significant loss of efficiency in scaling up due to such effects as shadowing between detectors.

Test results indicate that adequate intrinsic gamma ray efficiency (gamma ray rejection) is obtained for gamma exposure rates up to $100 \mathrm{mR} / \mathrm{hr}$ for the one paddle tested. The gamma rejection factor is estimated to be on the order of $10^{-8}$ for a dose rates up to $40 \mathrm{mR} / \mathrm{hr}$, which is similar to that obtained for ${ }^{3} \mathrm{He}\left(\sim 10^{-8}\right)$. It seems likely that the intrinsic gamma ray efficiency of the full size neutron detector will meet the required value of $10^{-6}$ in a $10 \mathrm{mR} / \mathrm{hr}$ field.

The GARRn value at a ${ }^{60} \mathrm{Co}$ exposure rate of $10 \mathrm{mR} / \mathrm{hr}$ is within the desired range. Testing of a full size system designed for use as a replacement for the ${ }^{3} \mathrm{He}$ based system in deployed systems will need to be evaluated to see whether the GARRn value remains in the acceptable range. 


\section{References}

ANSI. 2006. American National Standard for Evaluation and Performance of Radiation Detection Portal Monitors for Use in Homeland Security. Technical Report. ANSI 42.35, American Nuclear Standards Institute, Washington, D.C.

Ely J, Kouzes RT, Lintereur A, Schweppe J, Siciliano E, and Woodring M. 2009. BF Neutron Detector Testing and Comparison to ${ }^{3} \mathrm{He}$. PNNL-18581, Pacific Northwest National Laboratory, Richland, Washington.

Ely J, D Stromswold, and C Shepard. 2003. Radiation Portal Monitor Measurements. PIET-43741-TM014, PNNL-14110, Pacific Northwest National Laboratory, Richland, Washington.

Kouzes RT, Ely J, Lintereur A, Stephens D. 2009. Neutron Detector Gamma Insensitivity Criteria. PNNL -18903, Pacific Northwest National Laboratory, Richland, Washington.

Ely J and C Shepard. 2004. Test and Evaluation of the SAIC/Exploranium RPM8 Portal Monitor System. PIET-43741-TM-161, PNNL-16865, Pacific Northwest National Laboratory, Richland, Washington.

Kouzes RT, J Ely, and E Siciliano. 2007. Neutron Alarm Algorithms for Deployed RPMs. PIET-43741TM-663, PNNL-17101, Pacific Northwest National Laboratory, Richland, Washington.

Kouzes, RT, JH Ely, PE Keller, RJ McConn, and ER Siciliano. 2008. "Passive Neutron Detection for Interdiction of Nuclear Material at Borders." Nuclear Instruments and Methods in Physics Research Section A: Accelerators, Spectrometers, Detectors and Associated Equipment 584(2-3): 383-400.

Kouzes RT, ER Siciliano. 2009. ${ }^{3}$ He Neutron Detector Modification and BF $F_{3}$ Comparison. PIET-43741TM-838, PNNL-xxx, Pacific Northwest National Laboratory, Richland, Washington.

Kouzes, RT, 2009. “The ${ }^{3}$ He Supply Problem," Pacific Northwest National Laboratory Report PNNL18388.

Stromswold D, J Ely, R Kouzes, J Schweppe. 2003. Specifications for Radiation Portal Monitor Systems Revision 6.7. PIET-43741-TM-017, Pacific Northwest National Laboratory, Richland, Washington.

Van Ginhoven, RM, RT Kouzes, DL Stephens, 2009. “Alternative Neutron Detector Technologies for Homeland Security,” Pacific Northwest National Laboratory Report PNNL-18471. 


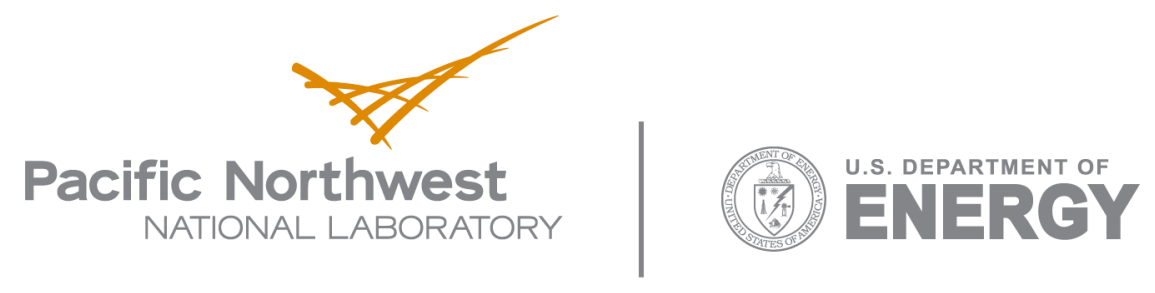

902 Battelle Boulevard

P.O. Box 999

Richland, WA 99352

1-888-375-PNNL (7665)

www.pnl.gov 